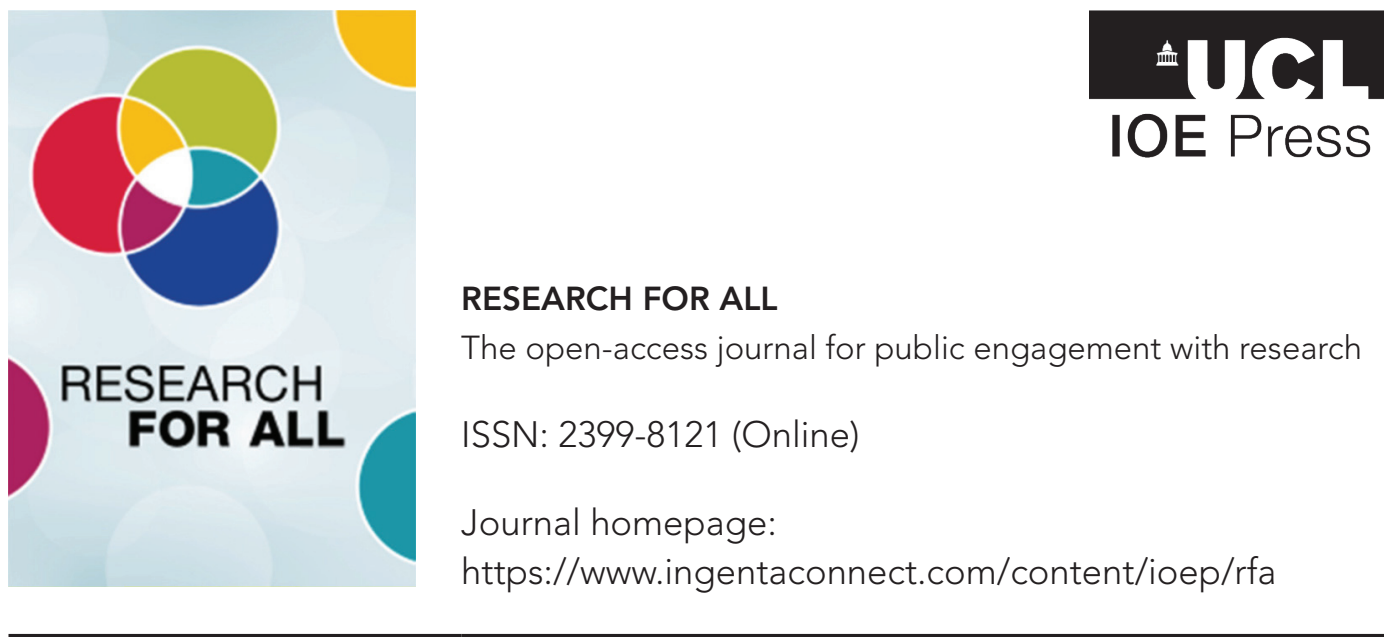

\title{
A collaborative approach to schools engagement training for university staff
}

Jessica Spurrell and Marcus Grace (i)

\section{How to cite this article}

Spurrell, J. and Grace, M. (2020) 'A collaborative approach to schools engagement training for university staff'. Research for All, 4 (1): 117-27. DOI https://doi.org/10.18546/RFA.04.1.09

Submission date: 4 September 2018

Acceptance date: 10 October 2019

Publication date: 1 February 2020

\section{Peer review}

This article has been peer reviewed through the journal's standard double-blind peer review, where both the reviewers and authors are anonymized during review.

\section{Copyright}

(C) Copyright 2020 Spurrell and Grace. This is an Open Access article distributed under the terms of the Creative Commons Attribution Licence (CC BY) 4.0 https://creativecommons.org/licenses/by/4.0/, which permits unrestricted use, distribution and reproduction in any medium, provided the original author and source are credited.

\section{Open access}

Research for All is a peer-reviewed open-access journal. 


\title{
A collaborative approach to schools engagement training for university staff
}

\author{
Jessica Spurrell* and Marcus Grace - University of Southampton, UK
}

\begin{abstract}
This paper describes the process of developing and delivering a new training programme to better equip university researchers to engage with and create interactive activities for schools. It has brought together people from within and beyond the university in many, often quite unexpected, ways. We discuss the points of learning for all involved, the strategic and logistical challenges faced, and offer some practical solutions to the challenges faced.
\end{abstract}

Keywords: school engagement, co-production, partnership, school-university, professional development, engaged research

\section{Key messages}

- Make the most of the experts on your doorstep by being open to where expertise can come from and by championing interconnectivity.

- It is the people that make projects great: getting the right people together can lead to some great things - giving them a focal point will consistently and efficiently lead to many more great things.

- Brokers or facilitators with capacity to follow up, support and investigate - and provide a human point of contact for all parties - are key for enabling this.

\section{Introduction}

Talk to US! was the University of Southampton (UoS) Schools-University Partnership Initiative (SUPI) - part of the national SUPI project funded by Research Councils UK/UK Research and Innovation (RCUK/UKRI) and coordinated by the National Co-ordinating Centre for Public Engagement (NCCPE) - which ran from 2013 to 2016. Today, it remains a point of contact platform between schools and the UoS, supported by the School-University Partnership Officer (SUPO), a role created as a direct result of the SUPI project, and guided by the SUPI principles of empathy and dialogue. (For more information on the School-University Partnerships Initiative, see NCCPE, 2018a.)

Talk to US! led to the development of training for UoS staff and students in creating interactive activities and workshops for schools for public engagement and widening participation. Widening participation refers to 'raising the aspirations and attainment of people from backgrounds that are under-represented at university ... to ensure that student bodies at universities reflect the diversity represented in wider society' (King's College London, n.d.). Findings from Talk to US!, the wider SUPI project and similar work have shown that: 
- interactions between school students and teachers with research help to bridge the gap between the school curriculum and 'real life' (Goldschmidt and Bogner, 2016)

- these interactions had maximum impact, and were most 'eye-opening', when they involved 'hands-on', interactive, enquiry-based activities for which students were given a sense of ownership (Spurrell et al., n.d.: 4, 14; Yeoman et al., 2017)

- the highest-quality activities were developed when researchers were able to work with teachers and each other to share ideas and best practice (Spurrell et al., n.d.; Yeoman et al., 2017).

This paper focuses on the half-day training programme for UoS staff and students that was developed based on these findings. The programme covers: understanding teacher, school student and researcher expectations; promoting student discussions; appropriate language and content; making your work relevant; activity planning; troubleshooting; and further support. It is based on the combined experience and expertise of teachers, UoS teacher trainers, and UoS public engagement and widening participation staff. It is delivered using a range of media and through the interaction techniques covered in the session. It is now integrated into the UoS Strategic Support to Expedite Embedding Public Engagement with Research (SEE-PER) training programme, and has been adapted to be delivered as part of the NCCPE training offer. (For more information on SEE-PER, see NCCPE, 2018b.)

The session has been very successful. One participant described it as: 'Fantastically informative and inspiring; anyone doing outreach should do this!' ('Outreach' is a term most often used to describe widening participation, but is also often used to refer to public engagement and other work involving communicating with external parties.) So far, 65 UoS staff and students have attended the session from a wide range of subject areas and career levels. Of participants completing evaluation forms, 68 per cent have rated the session as 'very good' and 32 per cent as 'good' on a five-point scale from 1 (very poor) to 5 (very good). Every participant has shared something that they will take forward from the session, and many have been in contact since to further develop their projects.

To get to the point of having a training session that an expert team are excited to deliver, and that the UoS research community are overwhelmingly enthusiastic about, has been a journey fraught with challenges, many of which came from unexpected areas. This paper presents these challenges, and the solutions we found through practice and reflecting on experience, in the hope of providing useful insight to the community.

\section{What happened: Finding and galvanizing expertise}

\section{Why create a new training session?}

Alongside the findings outlined in the Introduction, and in Spurrell et al. (n.d.), one of the major outputs of the Talk to US! SUPI was the Building School-University Partnerships Guide Book (Wager, 2016), a now internationally recognized (see, for example, Posner et al., 2016) resource for school-university partnership working. The Guide Book material leant itself well to a practical training session, and a suitable gap in our researcher development programme was identified: the number of UoS staff delivering material for schools was vast, often with little quality control and based on peer learning, and only one schools-specific training session was then available, the introductory Meet the Scientist training from LifeLab (Woods-Townsend et al., 2016). 
LifeLab is a unique engagement experience for local schools, combining cuttingedge medical research and health education (Woods-Townsend et al., 2015). Meet the Scientist - aimed at all researchers, not just those who identify as 'scientists' - enables researchers to 'go from zero to talking to teenagers'. Building on this, the combined forces of the learning encapsulated in the Guide Book and the experiences of teachers and teacher trainers could then enable researchers to develop interactive activities for school students, prepare for the logistics of working with schools and learn the importance of working with teachers.

\section{Who are we training?}

The programme is aimed at UoS staff and students who have had some experience of talking about research to a non-expert audience - for example, attending a Meet the Scientist session - and would like to do more-targeted engagement with schools. Of the 65 programme participants to date:

- 60 per cent were postgraduate research students

- 26 per cent were academic staff

- 11 per cent were professional services staff

- 3 per cent were undergraduate students.

The mix of experience and expectations of participants was one of the main points of consideration in the planning process - many discussions were had about how specifically the training session should be targeted in terms of role at the UoS, previous relevant experience and even school student age group. In the end, it was accepted that some variation would be inevitable, so the most practical option was to offer a training programme that could accommodate that. This worked surprisingly well, even with the greater than anticipated mix of experience that we ended up with in the pilot session, as word spread far wider than the carefully targeted communications. This is now a beneficial feature of the training, as many genuine and productive connections have been made between participants. This is in part due to the wonderful training delivery team, who are fantastic at facilitating peer learning between participants.

Initially, we also explored the concept of training that could be provided for both school and university staff, possibly together. However, with the particularly high demand and strong restrictions on teachers' time, combined with the vast amount of continuing professional development already available to them, we decided that this would require investing large amounts of time and expertise into developing a particularly robust and well-scrutinized programme. More feasible within the time frame of Talk to US! and the continuing SUPO role, therefore, was a programme purely for UoS staff and students. Furthermore, there was less of an urgent demand for such training for teachers: the collaborative interaction of teachers with the university was much less prevalent, and those who came forward to work with us were generally already very engaged.

\section{The development and delivery team}

The training development and delivery team came together in a very organic and unexpected way over a number of months. It required perseverance in the project, even when it seemed that, although there was enthusiasm and a clear need for the training, there was little capacity for the work. It also required an amount of opportunism, of asking a diverse range of people on the off-chance that they would be interested, and of talking about the project at every opportunity. This led to our first key learning 
point: make the most of the experts on your doorstep, and always be open to where expertise can come from.

The following examples illustrate the diversity of expertise and experience galvanized in the delivery team, as well as the organic nature by which the team came together:

- Marie is a modern foreign languages teacher in Weymouth (a town 60 miles/ $100 \mathrm{~km}$ from Southampton) who became involved with Talk to US! out of frustration at the lack of engagement from universities with her school. After a few meetings, including those in which the idea of a new training programme was mentioned, she and the SUPO (then Talk to US! project manager) delivered an ideas generation session to the UoS teacher training team, after which Marie's impressive teaching prowess became a common topic of conversation in the department.

- Susie is a Postgraduate Certificate in Education (PGCE) tutor in physical education and maths at the UoS. (In the UK, the PGCE is a one- or two-year academic qualification that can be achieved during teacher training.) Keen to expand her involvement in various projects at the UoS department Southampton Education School, she joined the training project as a result of the ideas generation session. Being equally familiar with both the school and university environments, she acted as an effective translator between the two 'worlds'. The teacher training team involvement also helped to raise the profile of the Education School within the university.

- Joe is a widening participation project leader at the UoS with recent teaching experience. He heard about the project at a team meeting shortly after joining the UoS and put himself forward to be involved. As with Susie, his familiarity with both school and university environments is invaluable.

- Emma is a science teacher in Romsey (a town 9 miles $/ 15 \mathrm{~km}$ from Southampton), who had worked with LifeLab to develop and deliver the Meet the Scientist training, and with the Public Engagement with Research unit (PERu) on the earliest iterations of their more general engagement training. However, she initially met the SUPO simply to discuss the end of Talk to US! after returning from maternity leave.

It is also noted that the contribution of Jess - then the Talk to US! project manager and now SUPO - was both facilitative and brought a researcher's perspective. She had carried out many outreach and engagement activities during her $\mathrm{PhD}$, and so could share personal experiences.

From the very first meetings, synergy between these people became apparent, which allowed the project to gather momentum and resilience. Despite the many other competing priorities of team members, one of the main reasons why they collectively devoted so much time and energy to the project was that not only were they invested in the project, but they were prepared to support each other. This must not be underestimated in its enabling of those involved to overcome the many challenges to work across institutions (and, indeed, counties).

Between the four of them, with their range of subject knowledge, personal and professional backgrounds, and current and previous roles and working environments, they had experienced and learnt from most scenarios that our researchers were likely to encounter when entering a school environment. They had also all undergone pedagogical training, and were therefore furnished with educational theory to dissect and describe these experiences. What are the tools that teachers use to maintain 
engagement with their students? How do they measure this engagement and adapt their delivery accordingly? What is the process they use to take a piece of information, or a direction of enquiry, and convert it into an interactive activity? How and why do these work? When do they not work? And what are the challenges faced in implementing them? This combination of both academic and practical experience and expertise was perfect both for finding out what our researchers needed to know and for enabling them to gain that knowledge. Once the content had been finalized, the delivery came very quickly and naturally, and their proactive approach meant that every aspect was covered, and everyone was able to cover their preferred aspects.

In hindsight, Marie, Susie, Joe and Emma seem the obvious choices for forming the development and delivery team for a schools engagement training session for researchers. They have the perfect combination of experience, expertise, institutional familiarity and enthusiasm. However, it was almost entirely due to circumstance that they found the project - and that the project was fortunate enough to find them. Lessons from Talk to US! and the wider SUPI project suggest that this is not unusual, nor is it something that can be controlled - it can, however, be controlled for. By championing interconnectivity, by openly sharing and discussing ideas, by valuing the diversity of expertise and experience of those immediately around us and those we happen upon by chance, and by putting a facilitator or broker - a human being among it all who has capacity to follow up, support and investigate, we are able to maximize the chances of such 'coincidences' playing out in our favour.

\section{What we learnt from what happened: Solutions from experience}

\section{Embedding collegiality and empathy through inter- and intra- institutional working}

As with many projects, the success of the training programme was dependent on the people involved, from the development and delivery team, to their senior management teams, to the participants in the programme themselves. Following from the benefits discussed in the previous section, the next examples highlight further benefits of championing interconnectivity as a way of working - our second key learning point, which draws particularly from reflections on active networking.

\section{An experiential approach to collaboration}

In school-university engagement, there is often a tendency for the process to be oneway, with schools as the passive receivers of the activity and universities as the active deliverers. Being part of the SUPI project highlighted other engagement models. Teachers and school students have a huge amount to offer any partnership and are generally very active players within them.

By actively working from the beginning with both in-house and local expertise, these groups were brought to greater prominence within the UoS. A dialogic way of working was adopted and, with its benefits being most effectively understood through such experience, this approach became further embedded in the cultures of the institutions. 


\section{Active networking}

Getting a diverse and like-minded group of people with similar interests together in a room can lead to some great things. Giving them a focal point around which to build their conversations, and through which their like-mindedness can be explored and exercised, will consistently and efficiently lead to many more great things. This was observed in both the development of the training and during the training itself.

The workshop development brought the following groups together in a productive and meaningful way, which has resulted in lasting working relationships:

- the directors of the Outreach and Widening Participation, PERu (Public Engagement with Research unit) and Southampton Education School teams through the strategic overview of the training

- the Outreach and Widening Participation and teacher training teams, with local teachers through the training development and delivery

- the main researcher development teams at the UoS, namely the Doctoral College and Centre for Higher Education Practice, with all of the teams mentioned above, through coordination of training on offer and publicizing the programme.

The training programmes themselves brought together and galvanized likeminded people (and continue to do so) from across and beyond the university, from undergraduates to professors, academics to library digital engagement managers, and, of course, local teachers. All share a passion for school-university partnership working, and the discussions generated, as well as the time to have these discussions and make these connections, are consistently reported as one of the highlights of the training, with answers to the evaluation question, 'What was the most useful part of the session?', including:

- 'networking opportunities'

- 'meeting/talking to teachers'

- 'to meet researchers in different areas to learn and share ideas together'.

\section{Support structures}

All of the training team were very fortunate in their management and peers, who supported them in this endeavour, when they could have easily, and not without reason, done the opposite by prioritizing other activities or being averse to the risk of a new endeavour that did not have guaranteed valuable outcomes.

In the UoS, the management teams of Susie, Joe and the SUPO were all involved in the project, not only from the start, but also in initiating the idea of creating a training session, so they were themselves invested in the project. In the schools, Marie included work on the training in her responsibilities in working with local primary schools, and Emma championed the professional development that this opportunity offered her both with the support of their management. All were given an encouraging balance of the freedom to develop the project as they wished, and support and guidance from management when required, which should not be underestimated.

As well as the supportive individuals involved, line managers themselves were supported in encouraging this endeavour, as it aligned to institutional and departmental goals and responsibilities - that there was substantial overlap between these across both departments and institutions was also a key enabling factor. 


\section{Processes and complexities of collaborative working, and how to meet them}

None of the many benefits and institutional changes described above came without challenges, from the logistic to the strategic. These are some of the challenges that we faced, and how we worked around them.

\section{Getting the team together to meet}

Teachers and those who work with schools have very complex and dynamic timetables. Finding common time to meet is itself a challenging exercise. Free online tools such as Doodle (https://doodle.com/free-poll) and TeamUp (www.teamup.com) are often very useful, although with competing and highly pressurized workloads, by the time everyone has completed a poll or shared their calendars, the information is often out of date as people's time gets booked up. Things also often change quite drastically at the last minute. Patience is very much required of the coordinator, as well as flexibility and clarity. Simple things such as reiterating the agreed time and date in every correspondence to ensure that everyone is up to date with current plans without scrolling through disjointed email chains can really help. Buy-in by all involved is also crucial to stop the project dropping off the bottom of a to-do list.

\section{Resourcing}

Money is often assumed to be a barrier for projects and, while this can be the case, a lot can be achieved on a small budget. The real value of financial investment in a project is in the institutional commitment to it that this generally brings. By various teams offering relatively small amounts of money - but more often resources and people's time - we found that many barriers were removed for us. For example:

- Being able to pay for cover for the teachers meant that they could be released from teaching to widen the windows in which they were available to work on the project. This, of course, also required buy-in from school senior management.

- The team pooled physical resources such as stationery, whiteboards and markers, and tablets, so that no one institution needed to purchase a full set of new resources.

- The UoS educational media team supported the project by helping create videos of interviews with students from Emma's school, creating a valuable resource that truly reflects the local context in which our researchers will most likely work, as well as further consolidating our relationship with that school - this has since been consistently mentioned as one of the most useful parts of the programme.

- Being able to provide refreshments for many of the planning meetings, and during the training itself, served to ensure the best use of available common free time slots, as a courtesy to all for giving up their time, and to improve attendance and participation in evaluation at the end of the training.

\section{Clarifying objectives and communication}

Rather than contributing content, the SUPO's role in the training planning meetings was generally to absorb all the contributions of the others, collate them, clarify them and feed them back to the group. This kept meetings moving and always ensured that, by the end of each meeting, everyone was clear about what they had achieved and any actions arising. 
Outside the planning meetings and the strategic meetings with Outreach and Widening Participation, PERu and Education School directors, the SUPO also took the opportunity to discuss the training concept with as many potential stakeholders as possible. Enthusiasm was mixed, but consistent enough that the concept was pursued and as much of this input as possible was considered. This helped to ensure that something genuinely useful was being created, and that there was a genuine desire to both deliver and participate. Key communication skills were required, such as effective questioning and listening, the ability to convey both interest in others' opinions and enthusiasm for the idea, patience, and realizing and respecting the value of everyone's perspectives.

This meant that there were many people invested in the project with their own objectives and motivations, which were as unique and diverse as the people involved, but always with some crossover. The SUPO's role included identifying these common themes and ensuring that they were articulated, so that everyone was clear about what they and everyone else were hoping to achieve. These objectives were often dynamic, and so the identification, clarification and articulation of objectives was a continuous process.

\section{Being prepared to 'let go'}

The fact that there were several months between deciding to create a training programme and finding the people to create it meant that we had to constantly ask ourselves if we were investing in something for which there was a genuine demand and that would be worth the time and energy taken to develop and deliver. It also required not being precious about any particular part of the concept, being ready to let all or any part of it go - but also being able to articulate the genuine value identified.

\section{Reflective practice and continuing development}

At the core of all teaching and learning is the principle of embedded reflective practice - the idea that evaluation is not just something that is done at the end of a project, lesson or activity for the benefit of someone unrelated, but that both as teachers and as learners we are constantly observing and thinking about ourselves and those around us, with the intention of improving how we learn and teach. This is so fundamental to education that the teachers, present and former, teacher trainers and pedagogical researchers involved in this project and the wider Talk to US! SUPI applied it constantly. For those of us from backgrounds in other disciplines, the concept was a revelation.

Reflective practice is therefore something that is woven through and discussed throughout the training programme, so that all the participants can benefit from it in both their work with schools and in their wider work.

Reflective practice was and is also applied by the development and delivery team, so that the programme is constantly evolving and improving. This is done:

- before each training session - when signing up, participants are asked to share their expectations for the session, and the team reflect on this as part of their preparation

- during each training session - participants start the training by revisiting their expectations and sharing them with each other; flexibility is built into the programme so the delivery team can focus on particular areas of interest brought up there and then, and change the pace to suit the participants' needs

- directly after each training session - participants complete evaluations, which are consolidated by the SUPO, bringing out key themes that the team then 
reflect on; after every three sessions or so the team come together and review the collective evaluations and update the training accordingly

- 'life after training' - where possible contact is maintained with training participants to offer them further support with their activity development, and to start to gather evidence of the long-term impact of the programme

- bespoke training - the training has been adapted to create bespoke programmes, for example, around a particular subject area or for the team behind an established activity that is in need of a fresh approach.

\section{Conclusions and summary}

In summary, producing a training workshop to enable researchers at the UoS to create engaging activities for schools has been a long and sometimes surprising journey:

- It has brought together people from across the university and beyond in many ways, not all of them expected, but all of them positive.

- It has highlighted the expertise that we are surrounded by but often miss, and given it multiple platforms for further recognition and collaboration.

- It has embedded empathy and collegiality across the institutions involved in many more ways than was anticipated.

- It has raised an awareness of the mechanisms through which this has taken place, such as active networking and the usefulness of a 'brokering' role such as the SUPO, and highlighted a need to continue to support and encourage these.

- It has been a learning experience for all involved, with many and varied skills practised and developed, from the strategic - such as finding new ways of sharing and developing an idea - to the logistical - such as finding new (and secret!) ways to book rooms.

- It has generated some valuable time for reflection on these experiences.

Finally, it has given us a story that we can share with the wider outreach, engagement and education communities. And we sincerely hope that, as our training programme encourages researchers to get school students thinking about their specialist knowledge, it is a story that has also got you thinking!

\section{Acknowledgements}

The authors would like to thank Kirsten Wythe for her incredible editing skills and Susie Fawcett for her feedback on early versions of this article, as well as her work on this project. Many thanks go also to Marie, Emma and Joe for their amazing work described here, and to Kirsten, Janice Griffiths and Steve Dorney, as well as Marie's and Emma's schools, for supporting this work.

\section{Notes on the contributors}

Jessica Spurrell is the School-University Partnership Officer (SUPO) at the University of Southampton, sitting between the Outreach and Widening Participation, Public Engagement with Research unit (PERu) and Southampton Education School teams, coordinating and supporting the university's engagement and outreach encounters with schools. She has an MEng degree in aerospace engineering with European studies and a PhD in cryogenic engineering and superconductivity. 
Marcus Grace is a professor of science education at the University of Southampton and former Head of the Southampton Education School. He is a doctoral supervisor and teaches on undergraduate, master's and postgraduate initial teacher training programmes. He was the Principal Investigator for the Talk to US! School-University Partnership Initiative and is a committed champion of engaged research in higher education.

\section{References}

Goldschmidt, M. and Bogner, F.X. (2016) 'Learning about genetic engineering in an outreach laboratory: Influence of motivation and gender on students' cognitive achievement'. International Journal of Science Education, Part B: Communication and Public Engagement, $6(2), 166-87$.

King's College London (n.d.) 'Frequently asked questions: What is "widening participation"?'. Online. www.kcl.ac.uk/study/widening-participation/faqs (accessed 30 August 2019).

NCCPE (National Co-ordinating Centre for Public Engagement) (2018a) 'School-university partnerships initiative'. Online. https://tinyurl.com/yby3yoca (accessed 11 November 2019).

NCCPE (National Co-ordinating Centre for Public Engagement) (2018b) 'Strategic support to expedite embedding public engagement with research'. Online. https://tinyurl.com/uj3y9bd (accessed 11 November 2019).

Posner, M.T., John, P.V., Wong, N.H.L., Mittal, V. and Nunez-Velazquez, M.M. (2016) 'From school classes to UNESCO: IYL-enabled environments for tackling the STEM skills shortage through student-led outreach'. SPIE Proceedings, Volume 9946: Optics Education and Outreach IV, 994607. Online. https://tinyurl.com/y3zbx4rm (accessed 31 October 2019).

Spurrell, J., Rietdijk, W. and Grace, M. (n.d.) RCUK Public Engagement with Research: SchoolUniversity Partnerships Initiative (SUPI) final report - University of Southampton. Online. https://tinyurl.com/y36p74ua (accessed 30 October 2019).

Wager, L. (2016) Building School-University Partnerships Guide Book: A planning document for university and school staff. Ed. Spurrell, J. Southampton: University of Southampton. Online. https://tinyurl.com/y697psaw (accessed 31 October 2019).

Woods-Townsend, K., Bagust, L., Barker, M., Christodoulou, A., Davey, H., Godfrey, K., Grace, M., Griffiths, J., Hanson, M. and Inskip, H. (2015) 'Engaging teenagers in improving their health behaviours and increasing their interest in science (evaluation of LifeLab Southampton): Study protocol for a cluster randomized controlled trial'. Trials, 16, Article 372, 1-9. Online. https://tinyurl.com/yybrdxbm (accessed 31 October 2019).

Woods-Townsend, K., Christodoulou, A., Rietdijk, W., Byrne, J., Griffiths, J.B. and Grace, M.M. (2016) 'Meet the scientist: The value of short interactions between scientists and students'. International Journal of Science Education, Part B: Communication and Public Engagement, 6 (1), 89-113.

Yeoman, K., Nardi, E., Bowater, L. and Nguyen, H. (2017) '"Just Google it?": Pupils' perceptions and experience of research in the secondary classroom'. British Journal of Educational Studies, 65 (3), 281-305. 